\title{
Consumo de gás natural na indústria de revestimentos cerâmicos brasileira
}

\section{(Consumption of natural gas in Brazilian ceramic tile industry)}

\author{
H. J. Alves, F. G. Melchíades, A. O. Boschi \\ Laboratório de Revestimentos Cerâmicos, Departamento de Engenharia de Materiais - DEMa \\ Universidade Federal de S. Carlos - UFSCar \\ Rod. Washington Luiz, km 235, C.P. 676, S. Carlos, SP 13565-905 \\ helton@ceramicaindustrial.org.br
}

\begin{abstract}
Resumo
O gás natural, atualmente, é a principal fonte de geração de energia térmica utilizada pelas indústrias de revestimentos cerâmicos no mundo e também é um dos itens que tem maior participação sobre o custo do produto acabado. Neste trabalho é apresentado um levantamento do consumo de gás natural realizado em uma indústria de via seca do pólo produtivo de Santa Gertrudes - SP, de modo que foi possível determinar o consumo específico de cada equipamento consumidor, bem como, identificar os "gargalos energéticos" do processo produtivo.
\end{abstract}

Palavras-chave: revestimentos cerâmicos, levantamento energético, consumo de gás natural.

\begin{abstract}
The natural gas is the main source of thermic energy generation used by ceramic covering industries around the world and it is also one of the itens which has the biggest weight over the finished product. In this work, it is presented a survey of the consumption of natural gas done in a factory of the productive pole of Santa Gertrudes-SP, which processes its products through a dry way, so that it was possible to determine the specific consumption of each consumer equipment, and also identify the "energetic necks" presented by the same.
\end{abstract}

Keywords: ceramic covering, energetic survey, consumption of natural gases.

\section{INTRODUÇÃO}

A produção de revestimentos cerâmicos em escala industrial requer um elevado consumo de energia térmica e elétrica, sendo estas, utilizadas em várias etapas ao longo de todo o processo produtivo. De maneira geral, as etapas que mais consomem energia são: secagem, moagem, atomização (no caso do processamento do material por via úmida) e queima. Um dos melhores indicadores da evolução da indústria de revestimentos cerâmicos é o estudo da evolução de seu consumo energético. Com o aprimoramento das técnicas referentes ao processo produtivo, o avanço tecnológico dos equipamentos e o aumento da produtividade, o consumo de energia elétrica e térmica aumentou progressivamente nas últimas décadas. Os custos com energia representam atualmente uma grande parcela do custo total de produção dessas indústrias.

Em alguns países como Espanha e Itália, que ocupam respectivamente o segundo e terceiro lugar na produção mundial de revestimentos cerâmicos, o conhecimento aprofundado sobre o consumo energético do setor, bem como o "mapeamento" energético realizado nas indústrias, têm possibilitado uma ação no sentido de racionalizar o uso da energia, o que implica em um maior aproveitamento da mesma e na redução de custos.
O Brasil, dentro deste cenário mundial, se destaca por ser o segundo maior produtor e consumidor, e o quarto maior exportador de revestimentos cerâmicos. Uma característica peculiar, é que as indústrias brasileiras utilizam duas rotas de processamento distintas para a fabricação de seus produtos: "via úmida" e "via seca". Atualmente, cerca de $65 \%$ da produção nacional é realizada utilizando a via seca [1]. Os pólos cerâmicos do Brasil concentram-se em duas regiões: Criciúma (Santa Catarina) e Santa Gertrudes (S. Paulo), sendo que a grande maioria das indústrias de via seca está localizada na região de Santa Gertrudes. Afirmase que a via seca é mais econômica do que a via úmida, principalmente em relação ao custo energético, todavia, não existem dados publicados sobre as diferenças de consumo energético das duas rotas de fabricação, obtidos de maneira sistemática e que permitam a comparação entre si. Podese dizer também que a grande parte dessas indústrias, não possui dados referentes ao consumo específico das etapas ou equipamentos que fazem parte do processo produtivo, quanto menos um controle/monitoramento interno que visa ações corretivas para a redução do consumo/custo.

Um fato observado em muitas indústrias do setor, é que poucas pessoas têm o acesso aos dados energéticos da empresa, considerando o mesmo como sendo sigiloso e que se divulgado pode trazer algum dano à estratégia de 
concorrência adotada. A validade destes dados muitas vezes é questionável, devido à falta de instrução sobre os locais onde as medidas de energia devem ser feitas, bem como, as condições dos medidores e equipamentos utilizados para quantificá-las. Além disso, quando a empresa tem o hábito de registrar os valores observados, os mesmos geralmente não são armazenados em um banco de dados, tornando-se "monopólio" de alguns funcionários, sendo descartados ou desaparecendo quando o funcionário deixa a empresa. A falta de um banco de dados faz com que o acompanhamento da evolução do consumo de energia se perca com o tempo.

Há pouquíssimos estudos que indicam de maneira direta o consumo de energia das indústrias de revestimentos cerâmicos. Em âmbito nacional e até mundial, existe um número limitado de trabalhos que tratam do tema.

Este trabalho apresenta os resultados de um levantamento do consumo de gás natural realizado em uma empresa de via seca do pólo produtivo de Santa Gertrudes - SP.

\section{O setor de revestimentos cerâmicos}

Nasúltimas décadas a indústria brasileira de revestimentos cerâmicos tornou-se altamente automatizada, fato este que contribuiu para a expansão de sua produção. Nos últimos doze anos (de 1994 a 2005) a produção de revestimentos duplicou, e como resultado dessa expansão houve uma significante redução dos preços, o que popularizou o uso dos revestimentos cerâmicos.

Atualmente, a indústria cerâmica representa um setor de grande importância econômica para o Brasil, isso pode ser observado por sua participação no PIB (Produto Interno Bruto), alcançando um valor da ordem de $1 \%$. Dentro deste contexto a cerâmica de revestimento é um dos mais importantes segmentos e apresenta um crescente desempenho tecnológico.

O crescimento da indústria de revestimentos é uma tendência mundial. Em 1995 foram produzidos globalmente 3,2 bilhões de $\mathrm{m}^{2}$ de revestimentos cerâmicos, distribuídos na Ásia (40\%), Europa (40\%), América do Sul (14\%), América do Norte (3\%) e África (3\%). Em 1998, somente a produção dos cinco maiores países produtores atingiu 3,1 bilhões de $\mathrm{m}^{2}$, superando em 2005 o valor de 4,0 bilhões de $\mathrm{m}^{2}$ [1].

O mercado mundial de revestimentos cerâmicos segue uma tendência de crescimento, em que a China é líder em produção e consumo. O Brasil, com sua produção crescente tende, nos próximos anos, a se distanciar da Itália e a Espanha, consolidando sua permanência como segundo maior produtor mundial.

O setor de revestimentos cerâmicos se caracteriza pelo grande dinamismo e rapidez na adaptação aos avanços tecnológicos. Nas últimas décadas, a introdução de novas tecnologias, como por exemplo, a monoqueima, a substituição dos fornos túnel por fornos a rolo e a redução dos ciclos de queima dos produtos, provocaram uma profunda modernização das empresas e o aumento da competitividade entre as mesmas. Em um cenário onde a redução de custos está intimamente relacionada ao fato de tornar o produto mais acessível ao consumidor, e consequentemente aumentar sua participação no mercado, qualquer ação que venha a contribuir neste sentido é bem quista pelas empresas.

\section{Uso da energia na indústria de revestimentos cerâmicos}

O processo de produção de revestimentos cerâmicos requer um elevado consumo energético, o qual reflete efetivamente na composição dos custos de produção. Sabese que, na Itália, os gastos com energia representam cerca de $23 \%$ do custo médio total de produção, o que evidencia o custo energético como um dos que mais tem peso sobre o preço do produto acabado [2]. A necessidade de diminuir a energia utilizada pelas indústrias é um tema bastante abordado na atualidade, tanto por fatores ambientais importantes, como o esgotamento de fontes de energia primária, como por exemplo, o gás natural, quanto pela de redução de custos, o que tem levado muitas empresas a se preocuparem de uma forma mais efetiva com a questão energética.

A energia utilizada pela indústria de revestimentos cerâmicos pode ser dividida em dois tipos: energia elétrica e energia térmica. A evolução do consumo de energia térmica e elétrica no setor de revestimentos cerâmicos nas últimas décadas pode ser acompanhada pelo crescimento da produção mundial. Dentre as poucas publicações existentes sobre o tema, merece destaque um levantamento realizado no setor de revestimentos cerâmicos espanhol, onde se pode observar que em uma década (de 1985 a 1995) o consumo de energia elétrica e térmica praticamente quadruplicou, sendo que neste mesmo período a produção de revestimentos na Espanha quase triplicou. É importante ressaltar que a produção espanhola continuou aumentando progressivamente nesta última década, passando de 400 milhões de $\mathrm{m}^{2}$ em 1995 para 648 milhões de $\mathrm{m}^{2}$ em 2005 [3].

\section{Energia térmica - gás natural}

O gás natural é uma fonte de energia primária, constituído pela mistura de metano e outros hidrocarbonetos gasosos, originados da decomposição de matéria orgânica fossilizada ao longo de milhões de anos. O gás natural temse mostrado cada vez mais competitivo em relação a vários outros combustíveis, tanto no setor industrial como no de transporte e na geração de energia elétrica [4].

$\mathrm{Na}$ Europa, muitos países não possuem reservas significativas de gás natural, porém extensos gasodutos atravessam praticamente todo o continente levando gás para os mais diversos segmentos de mercado. Trata-se da "integração energética", que só teve início no Brasil recentemente através da implantação do gasoduto Bolívia-Brasil, o maior empreendimento da América do Sul nos anos 90. A prática de integração energética é difundida com sucesso por toda a Europa, a Inglaterra, por exemplo, possui pouquíssimas reservas de gás natural, porém a participação deste energético na matriz do país é de aproximadamente 30\% [5]. 
No Brasil, o gás natural é o energético que vem apresentando as maiores taxas de crescimento na matriz energética do país, tendo mais que dobrado a sua participação na oferta interna de energia nos últimos anos, passando de 3,7\% (1998) para 9,3\% (2005). Sua produção e importação cresceram em $2005,4,3 \%$ e $11,3 \%$, respectivamente. Isso se deve, principalmente, por sua eficiência na substituição de outros combustíveis derivados do petróleo como: óleo combustível, gás liquefeito de petróleo (GLP) (na indústria), e gasolina (no transporte) [6].

O gás natural, atualmente, é a principal fonte de geração de energia térmica utilizada pelas indústrias de revestimentos cerâmicos no mundo. As etapas do processamento do material cerâmico que necessitam de calor, para que todas as transformações físico-químicas aconteçam, são: atomização (via úmida), secagem e queima. No cenário brasileiro, o estado de S. Paulo é o maior produtor nacional de revestimentos cerâmicos, onde mais de $60 \%$ das indústrias do setor estão concentradas. A participação do consumo de gás natural do setor cerâmico sobre o volume total que é comercializado dentro do estado representa 16\%, ocupando o segundo lugar e ficando somente atrás da indústria química/petroquímica [7].

Um fator vantajoso que contribui com o emprego do gás natural na indústria de revestimentos cerâmicos brasileira é a localização geográfica dos principais pólos produtivos em relação às redes de gasodutos existentes nas regiões Sul e Sudeste. A proximidade das fábricas em relação ao gasoduto Bolívia-Brasil, permite melhores possibilidades de ampliação do uso do gás natural nesta atividade produtiva.

A grande parte do valor do custo energético das indústrias de revestimento cerâmicos pode ser atribuída ao gás natural. Isso faz com que as empresas busquem alternativas para aumentar sua eficiência, através da diminuição do consumo e aumento da produtividade.

\section{MATERIAIS E MÉTODOS}

Foi escolhida para este estudo uma indústria de revestimentos cerâmicos de via seca, localizada no pólo produtivo de Santa Gertrudes, SP, que apresentava aparentemente um consumo de gás natural elevado. Esta indústria não possuía nenhum tipo de indicativo de consumo específico dos secadores e dos fornos (equipamentos consumidores), bem como, apresentava alguns equipamentos medidores quebrados ou posicionados em locais errados ao longo das linhas de produção.

As medições do consumo de energia térmica (gás natural) devem ser feitas através de leituras do volume de gás consumido em um determinado intervalo de tempo, sendo também necessário conhecer os valores de pressão e temperatura nos pontos da tubulação que antecedem a entrada de gás nos secadores e fornos. O conhecimento dos valores de pressão nas proximidades do ponto onde é realizada a medição do volume é de fundamental importância para que o valor do volume observado seja corrigido através de uma padronização, de forma que, todas as medidas realizadas possam ser comparativas [8].
Para que se possa determinar, em uma tubulação de gás, os valores de pressão e volume consumido, é necessário que estejam devidamente instalados os seguintes equipamentos medidores:

- Contador: mede continuamente o volume total de gás que passa pela tubulação. Na maioria das instalações de gás natural utilizam-se contadores volumétricos do tipo "turbina", onde o fluxo laminar do gás move uma espécie de hélice, cujo movimento é transformado em pulsos elétricos que são processados e enviados para um indicador de leitura digital, podendo ser visualizados os valores totalizados de volume $\left(\mathrm{m}^{3}\right)$ e de vazão $\left(\mathrm{m}^{3} / \mathrm{min}\right)$. Em alguns casos também podem ser encontrados nas instalações, indicadores de leitura mecânicos, que apresentam somente a leitura do volume total de gás consumido;

- Manômetro: mede a pressão dinâmica do gás na tubulação. Geralmente, os manômetros encontrados nas indústrias são do tipo analógico, sendo capazes de indicar valores de pressão confiáveis;

- Termômetro: indica a temperatura em que o gás está presente na tubulação. O conhecimento do valor da temperatura é importante para os cálculos de padronização, uma vez que, interfere diretamente nos valores de pressão e de volume.

A Fig. 1 apresenta um esquema que ilustra o correto posicionamento dos equipamentos de medida em uma tubulação de gás.

A primeira ação tomada consistiu em adequar os equipamentos medidores, através da troca, substituição e correto posicionamento dos mesmos.

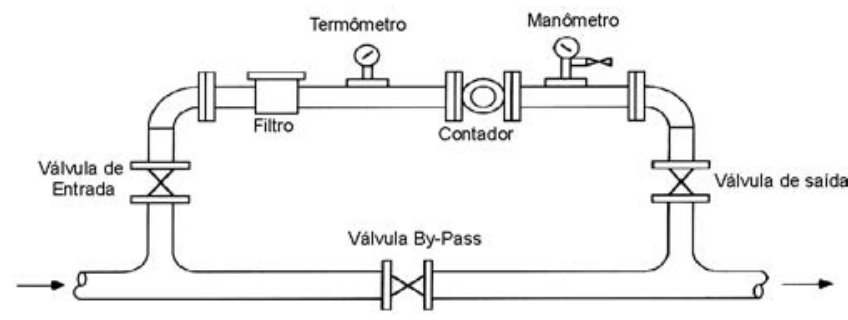

Figura 1: Esquema do posicionamento dos equipamentos de medida em uma tubulação de gás [8].

[Figure 1: Outline positioning of equipment for the measure in gas pipe [8].]

O conhecimento prévio de algumas informações gerais foi necessário, tais como: produção mensal, tipologia, formato, espessura e relação $\mathrm{Kg} / \mathrm{m}^{2}$ de produto, número de linhas de produção, equipamentos consumidores de energia, capacidade e produtividade de cada equipamento, etc. Outras informações específicas, também foram essenciais para realizar o levantamento energético e interpretar os resultados: dados do cavalete externo (ponto onde o gás sofre a despressurização inicial, deixando a tubulação externa e passando para o interior das instalações da indústria);

- posicionamento e funcionamento dos medidores de pressão (manômetros) e indicadores de vazão, instalados ao 
longo das tubulações de gás nas linhas de produção;

- valor do poder calorífico inferior do gás natural fornecido pela companhia abastecedora;

- tipo de classe em que a empresa se encontra dentro do quadro de tarifação vigente;

- consumo mensal ( $\left.\mathrm{m}^{3} / \mathrm{mês}\right)$.

As medições do consumo de gás natural foram feitas através de leituras periódicas do volume de gás consumido em um determinado intervalo de tempo (entre os turnos), através dos valores registrados nos aparelhos indicadores digitais de vazão e nos totalizadores mecânicos de volume. Os valores de pressão foram obtidos pela leitura direta nos manômetros instalados ao longo da tubulação (próximos aos medidores que antecedem a entrada de gás nos secadores e nos fornos). No caso da temperatura em que o gás natural se apresenta no interior da fábrica (nas condições das medidas de pressão e de volume), foi considerado um valor acrescido de cerca de $2{ }^{\circ} \mathrm{C}$ em relação ao registrado no cavalete externo. A padronização do volume foi feita a partir do desenvolvimento matemático da equação dos gases ideais (equação A) [9]:

$$
\frac{\mathrm{PV}}{\mathrm{T}}=\mathrm{nR}
$$

onde $P=$ pressão (mbar), $n=$ número de moles (mol), $V=$ volume $\left(\mathrm{m}^{3}\right), T=$ temperatura $(\mathrm{K}), R=$ constante dos gases ideais $\left(\mathrm{m}^{3} \cdot \mathrm{mbar} / \mathrm{mol} . \mathrm{K}\right)$.

Após a obtenção dos valores medidos e padronizados, referentes ao consumo de gás dos equipamentos, foi calculado o volume total mensal consumido, medido no interior da indústria. Assim, pôde-se confrontar o volume total medido, com o que foi registrado no cavalete externo, onde a companhia abastecedora realiza as leituras para o cálculo da conta a ser paga pela indústria. Estes valores de volume devem ser muito próximos, de modo que seja possível testar a eficiência da metodologia e as condições dos equipamentos medidores.

\section{RESULTADOS E DISCUSSÃO}

A fábrica analisada apresentava quatro linhas de produção, que continham um secador e um forno cada. A produção mensal de revestimentos cerâmicos gira em torno de $1.850 .000 \mathrm{~m}^{2}$, enquanto que o consumo médio mensal de gás natural é de $2.000 .000 \mathrm{~m}^{3}$.

A Tabela I apresenta um resumo dos resultados de consumo específico de gás natural dos secadores e fornos em três unidades: $\mathrm{m}^{3} / \mathrm{mês}, \mathrm{m}^{3} / \mathrm{m}^{2}$ e $\mathrm{kcal} / \mathrm{kg}$, referentes ao mês de fevereiro/2007. Os valores expressos em $\mathrm{kcal} / \mathrm{kg}$ são os mais importantes de todos, pelo fato de possibilitar a determinação da quantidade de energia real envolvida no processamento de certa quantidade de massa de material produzido, bem como, permitir a comparação entre produtos que apresentam espessuras diferentes.

Pode-se notar, de maneira geral, que existem diferenças no consumo térmico entre os mesmos tipos de equipamentos de linhas de produção diferentes. Observa-se que a Linha 1 é a que apresenta o maior consumo de todas, principalmente pelo elevado consumo do Secador 1. A Linha 2 aparece em segundo lugar, devido ao alto valor de consumo térmico apresentado pelo Forno 2. Já as Linhas 3 e 4 possuem valores de consumo parecidos, sendo as mais econômicas no consumo de gás natural da fábrica. É válido destacar que o menor volume consumido pela Linha 2 , em $\mathrm{m}^{3} / \mathrm{mês}$, é devido ao fato da mesma apresentar uma menor produtividade em relação às demais linhas de produção, o que é corrigido quando se observa o valor do consumo nas outras unidades de medida: $\mathrm{m}^{3} / \mathrm{m}^{2}$ e $\mathrm{kcal} / \mathrm{kg}$.

O monitoramento diário do consumo de gás natural (GN) dos secadores e fornos da fábrica pode ser observado nas Figs. 2 e 3, respectivamente.

A Fig. 2 evidencia a diferença existente entre o consumo dos secadores da fábrica, onde é possível notar o elevado valor apresentado pelo Secador 1, e uma similaridade no perfil de consumo dos Secadores 2, 3 e 4.

$\mathrm{Na}$ Fig. 3 a maior diferença observada é entre os consumos dos Fornos 2 e 3, onde o Forno 2 é o que possui o maior consumo de gás natural. Também nota-se nas Figs. 2 e 3 que existem variações no consumo específico de cada equipamento ao longo dos dias do mês. Estas variações são mais acentuadas para os fornos do que para os secadores.

Na Fig. 4 estão presentes os valores comparativos do consumo térmico específico em $\mathrm{kcal} / \mathrm{kg}$ das quatro linhas de produção da fábrica. Pode-se verificar que a Linha 1 possui

Tabela I - Valores corrigidos de consumo de gás natural dos secadores e fornos das diferentes linhas de produção. [Table I - Corrected values of natural gas consumption from dryers and kilns of different lines of production.]

\begin{tabular}{|c|c|c|c|c|c|c|c|c|c|c|c|c|}
\hline \multirow[t]{2}{*}{$\mathrm{x}$} & \multirow[t]{2}{*}{$\begin{array}{l}\text { Formato } \\
\mathrm{cm} \mathrm{x} \mathrm{cm}\end{array}$} & \multicolumn{2}{|c|}{$\begin{array}{l}\text { Produtividade } \\
\left(\mathrm{m}^{2} / \mathrm{dia}\right)\end{array}$} & \multicolumn{3}{|c|}{$\begin{array}{l}\text { Consumo } \\
\left(\mathrm{m}^{3} / \mathrm{mês}\right)\end{array}$} & \multicolumn{3}{|c|}{$\left(\mathrm{m}^{3} / \mathrm{m}^{3}\right)$} & \multicolumn{3}{|c|}{$\begin{array}{l}\text { Consumo } \\
\text { (kcal/kg) }\end{array}$} \\
\hline & & Secador & Forno & Secador & Forno & Total & Secador & Forno & Total & Secador & Forno & Total \\
\hline Linha 1 & $38 \times 38$ & 15.986 & 15.695 & 199.468 & 346.162 & 545.630 & 0,45 & 0,79 & 1,23 & 272,7 & 481,1 & 753,8 \\
\hline Linha 2 & $29 \times 43$ & 10.408 & 10.297 & 79.627 & 236.845 & 316.473 & 0,27 & 0,82 & 1,10 & 163,8 & 492,8 & 656,6 \\
\hline Linha 3 & $45 \times 45$ & 17.200 & 16.712 & 147.646 & 332.951 & 480.597 & 0,31 & 0,71 & 1,02 & 182,4 & 422,1 & 604,5 \\
\hline Linha 4 & $45 \times 45$ & 18.119 & 17.886 & 140.195 & 386.225 & 526.419 & 0,28 & 0,77 & 1,05 & 164,5 & 459,6 & 624,2 \\
\hline Média & - & - & - & 141.734 & 325.546 & 467.280 & 0,33 & 0,77 & 1,10 & 195,9 & 463,9 & 659,8 \\
\hline
\end{tabular}


Evolução do Consumo de GN dos Secadores

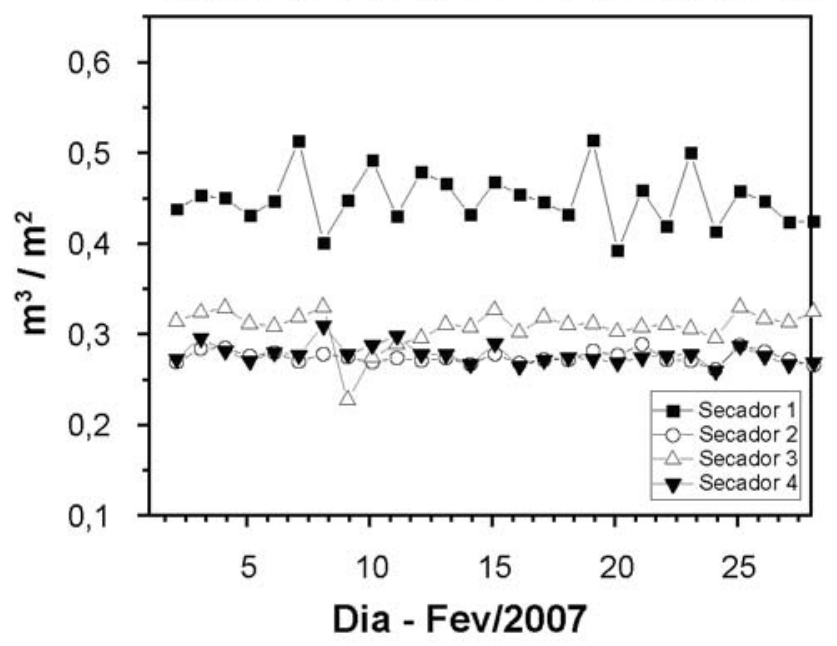

Figura 2: Monitoramento diário do consumo de gás natural dos secadores da fábrica.

[Figure 2: Tracking daily consumption of natural gas dryers of the plant.]

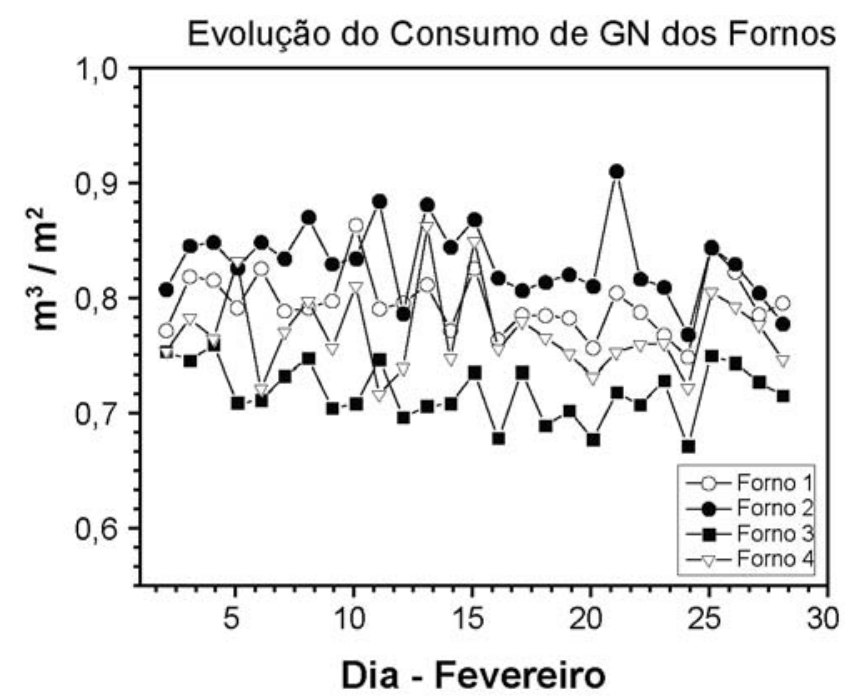

Figura 3: Monitoramento diário do consumo de gás natural dos fornos da fábrica.

[Figure 3: Tracking daily consumption of natural gas kilns of the plant.]

o maior consumo térmico, cerca de $150 \mathrm{kcal} / \mathrm{kg}$, ou $25 \%$ de incremento em ralação à Linha 3, que apresenta o menor valor. Quando se leva em conta o preço do gás natural e o quanto esta diferença representa em $\mathrm{m}^{3} / \mathrm{mês}$, é possível afirmar que uma empresa que possui uma discrepância de consumo desta ordem de grandeza, está deixando de economizar um montante de cerca de R\$ 2.000.000/ano. Aliado a este fato, ainda merece destaque, a possibilidade de redução do consumo de gás natural, que é uma fonte não renovável de energia. A Fig. 4 ainda revela a diferença entre o consumo entre cada equipamento da fábrica.

Fazendo-se um balanço sobre o consumo térmico global da fábrica é possível dizer que o consumo de energia térmica envolvido na produção de revestimentos cerâmicos é de aproximadamente $660 \mathrm{kcal} / \mathrm{kg}$, conforme pode ser visto na Tabela I. Dessa forma, pôde-se calcular a participação do consumo médio dos secadores e fornos sobre o consumo térmico global da fábrica (Fig. 5). Os fornos são responsáveis pelo consumo de $70,3 \%$ do total de gás natural necessário para o processamento do material, sendo os secadores consumidores de $29,7 \%$.

O volume total consumido pela fábrica, registrado no cavalete externo, durante o período do mês de fevereiro foi de $1.854 .238 \mathrm{~m}^{3}$. O valor do volume totalizado e corrigido das leituras no interior da fábrica foi de $1.869 .119 \mathrm{~m}^{3}$. Isso indica uma correlação de cerca de $100,8 \%$ entre o volume consumido pago pela empresa e o que foi obtido através da soma dos consumos medidos de cada equipamento no interior da fábrica.

$\mathrm{O}$ erro obtido foi igual a $0,8 \%$, sendo atribuído, principalmente, aos possíveis erros na leitura dos equipamentos medidores. Dessa forma, pôde-se confirmar a eficiência da metodologia desenvolvida e também verificar o bom desempenho dos equipamentos medidores.

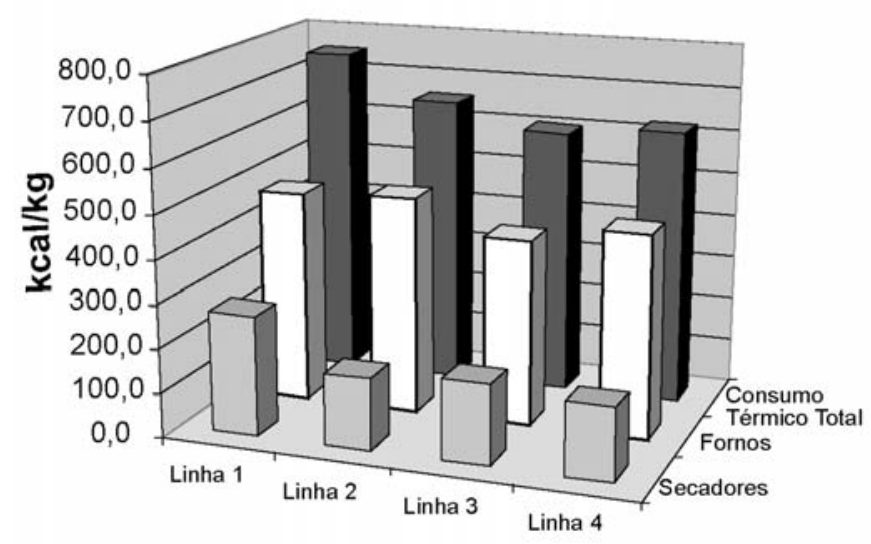

Figura 4: Consumo térmico em $\mathrm{kcal} / \mathrm{kg}$ dos equipamentos e linhas de produção da fábrica.

[Figure 4: Consumption heat in kcal/kg of equipment and production lines for the plant.]

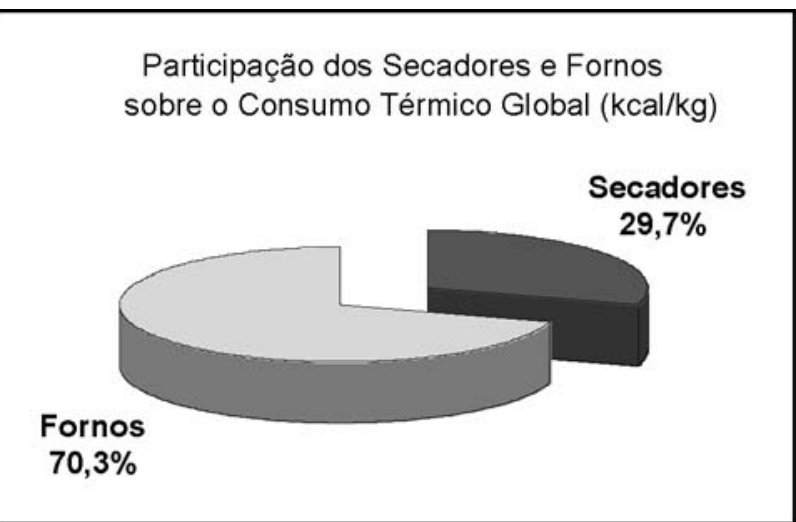

Figura 5: Participação do consumo dos secadores e fornos sobre o consumo térmico global da fábrica, expresso em $\mathrm{kcal} / \mathrm{kg}$.

[Figure 5: Participation in the consumption of dryers and kilns on the overall thermal consumption of the plant, expressed in $\mathrm{kcal} / \mathrm{kg}$.] 


\section{CONCLUSÕES}

O levantamento inicial do consumo térmico realizado permitiu: obter medidas precisas e confiáveis de pressão e volume; conhecer o consumo específico de gás natural de todos os secadores e fornos da fábrica; identificar previamente os principais "gargalos energéticos" (Forno 2 e Secador 1); constatar o elevado consumo de gás natural dos secadores, quando comparados com os consumos apresentados por outras indústrias de via seca da região de Santa Gertrudes, que produzem produtos semelhantes.

A continuidade do monitoramento do consumo de gás natural da fábrica através das medições periódicas, bem como o estudo das variáveis presentes nos fornos e secadores, é necessária para realizar um trabalho de gestão e eficiência energética na empresa.

\section{REFERÊNCIAS}

[1] ANFACER - Associação Nacional de Fabricantes de Cerâmica de Revestimento. Disponível em www.anfacer. org.br, data da consulta 14/06/2007.
[2] G. P. Crasta, Costi e ricavi dell'industria ceramica italiana, Ceramic World 16, 65 (2006) 46-50.

[3] J. E. Enrique, Evolución de los consumos de energía térmica y eléctrica en el sector de baldosas cerámicas. Técnica cerámica, España 246 (2006).

[4] AIE - Agência Internacional de Energia, World Energy Outlook 2006 Edition. Disponível em www.iea.org/textbase/ weo/free.asp, data da consulta 16/05/2007.

[5] S. E. G. Moraes, "O Mercado de Gás Natural no Estado de S. Paulo", Tese de Doutorado em Energia, Universidade de S. Paulo, USP (2003) pp. 17-18.

[6] Ministério de Minas e Energia. Balanço Energético Nacional - Resultados Preliminares 2006. Disponível emwww.ben.epe.gov.br/script/BenResultadosPre2006. asp?CodSecao=2, data da consulta 20/08/2007.

[7] Comgás - Companhia de Gás de S. Paulo. Disponível em www.comgas.com.br, data da consulta 25/09/2007.

[8] G. Nassetti, Piastrelle Ceramiche \& Energia, Centro Ceramico, Bologna, Itália (1998) 20.

[9] T. L. Brown, H. E. Lemay, B. E. Bursten, Química Ciência Central, $7^{\text {a }}$ Ed., LTC Editora, Rio de Janeiro (1997) 230.

(Rec. 31/10/2007, Ac. 27/12/2007) 